\title{
EDUCAÇÃO SUPERIOR EM TEMPOS DE PANDEMIA: DIREITO TEMPORÁRIO APLICÁVEL E SEU ALCANCE
}

\author{
Horácio Wanderlei Rodrigues ${ }^{1}$
}

\section{RESUMO:}

O artigo visa elucidar os principais pontos constantes das normas editadas adotando procedimentos temporários, no âmbito da educação superior - especificamente no sistema federal de educação -, durante o período de duração da Pandemia de Covid-19. Inclui - no corpo do artigo - a análise das Portarias MEC n. ${ }^{\circ} 343 / 2020$, n. ${ }^{\circ} 345 / 2020$ e n. ${ }^{\circ}$ 395/2020, da Portaria CAPES n. ${ }^{\circ}$ 36/2020 e da Medida Provisória n. ${ }^{\circ}$ 934/2020. No apêndice encontra-se a análise da Portaria MEC n. ${ }^{\circ}$ 544/2020 e do Parecer CNE/CP n. ${ }^{\circ}$ 5/2020. Busca descrever e esclarecer o conteúdo desse conjunto normativo em termos de limites e possibilidades. Inclui sugestões relativas aos problemas apontados.

Palavras-chave: Educação Superior; Direito Temporário; Portaria MEC n. ${ }^{\circ}$ 343/2020; Portaria MEC n. ${ }^{\circ}$ 544/2020; Parecer CNE/CP n. ${ }^{\circ}$ 5/2020.

\section{HIGHER EDUCATION IN PANDEMIC TIMES: APPLICABLE TEMPORARY LAW AND ITS SCOPE}

\begin{abstract}
:
The article aims to elucidate the main points contained in the edited rules by adopting temporary procedures, within the scope of higher education - specifically in the federal education system -, during the duration of the Covid-19 Pandemic. It includes - in the body of the article - the analysis of MEC Ordinances No. 343/2020, No. 345/2020 and No. 395/2020, of CAPES Ordinance No. 36/2020 and Provisional Measure No. 934 / 2020. In the appendix there is an analysis of MEC Ordinance No. 544/2020 and Opinion CNE / CP No. 5/2020. It seeks to describe and clarify the content of this normative set in terms of limits and possibilities. Includes suggestions regarding the problems mentioned.
\end{abstract}

Key works: Higher education; Temporary Law; MEC Ordinance No. 343/2020; CAPES Ordinance No. 544/2020; Opinion CNE/CP No. 5/2020.

\section{INTRODUÇÃO}

A pandemia causada pelo Coronavírus está tendo impacto em praticamente todas as atividades humanas. E na educação esse impacto foi direto e imediato, com a paralisação de todas as atividades de ensino-aprendizagem, da pré-escola à educação superior.

\footnotetext{
1 Doutor e Mestre em Direito pela UFSC. Estágios de Pós-Doutorado em Filosofia na UNISINOS e em Educação na UFRGS. Professor Permanente e Coordenador do PPGD/UNIVEM. Professor Convidado do PPGD/UNICURITIBA. Bolsista de Produtividade em Pesquisa do CNPq. e-mail: horaciowr@gmail.com
} 
Este artigo visa elucidar os principais pontos constantes das normas editadas adotando procedimentos temporários, no âmbito da educação superior - especificamente no sistema federal de educação -, durante o período de duração da Pandemia da Covid-19, a saber:

- Portarias MEC n. ${ }^{\circ}$ 343/2020, n. ${ }^{\circ}$ 345/2020 e n. 395/2020 - substituição das aulas presenciais por aulas que utilizem meios e tecnologias de informação e comunicação, ou, alternativamente, sua suspensão; no apêndice será analisada a Portaria MEC n. ${ }^{\circ}$ 544/2020, que as revogou;

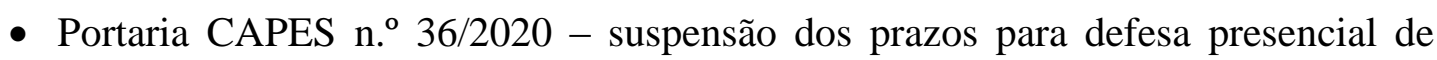
dissertações e teses e possibilidade de realização de bancas por meio de tecnologias de comunicação à distância;

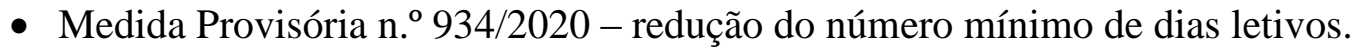

A análise realizada trata do conjunto normativo vigente na data em que foi escrito, buscando descrever e esclarecer seu conteúdo em termos de limites e possibilidades. Ainda, contém sugestões e orientações relativas às lacunas existentes. É nesse, segundo aspecto, mais prescritivo.

Por se tratar de análise de legislação nova e temporária, sobre a qual não há trabalhos escritos e publicados e nem decisões administrativas ou judiciais conhecidas, as referências estão restritas fundamentalmente à legislação consultada, à exceção de um pequeno trabalho já publicado sobre o tema.

\section{DIREITO TEMPORÁRIO E PRAZOS ESTABELECIDOS}

Neste artigo utiliza-se a expressão Direito Temporário para indicar um determinado conjunto de normas, editado para regular uma situação delimitada em termos de espaço temporal. São normas que, passado o fato que motivou a sua edição, deixam de ter aplicação. Sua vigência é limitada ao período específico indicado na própria norma, que pode ser um número específico de dias - com data exata de início e fim - ou o período de tempo durante o qual o fato persistir.

No caso da Pandemia do Covid-19, o Direito Temporário editado especificamente na área educacional tem tido seu prazo de validade definido nas próprias normas, iniciando com 
a sua publicação e se prolongando por um período determinado de tempo. Esse período de tempo, sendo necessária a sua ampliação, é prorrogado através da edição de nova norma.

Embora o Direito Temporário seja relativo ao regramento de situações específicas, em um espaço temporal devidamente delimitado, seus efeitos se prolongam no tempo. O que ocorre no período estabelecido, nos termos das normas temporárias, permanece integralmente válido, de forma definitiva. É a situação das normas que permitem a substituição das aulas presenciais por aulas remotas e as quer permitem bancas integralmente realizadas através de tecnologias de comunicação à distância.

Há também as normas que estabelecem uma determinada possibilidade, delimitada no tempo, mas que exigirá a prática, no futuro, de ações compensatórias. É o caso das normas que estabelecem a possibilidade de suspensão do calendário escolar. Nesse caso, após o término do período regrado pelo Direito Provisório, haverá um outro período, no qual os atos não praticados terão de ser realizados, substituídos ou compensados, nos termos de outras normas transitórias complementares, de caráter regulamentar.

Há, ainda, as normas que estabelecem o próprio período durante o qual as partes às quais elas se dirigem podem delas se utilizar. Nesse caso, estão aquelas destinadas a adotar, ou não, uma determinada possibilidade prevista no Direito Transitório. É o caso da utilização da faculdade de substituição das atividades presenciais, por atividades remotas, estabelecida na Portaria MEC n. ${ }^{o}$ 343/2020. Sua utilização tinha um prazo de quinze dias para que houvesse a comunicação ao Ministério de Educação (MEC) - artigo $1^{\circ}$, parágrafo $5^{\circ}$, com a redação dada pela Portaria MEC n. ${ }^{\circ}$ 345/2020 -, encerrado em 3 de abril de 2020.

Como todos os demais prazos estabelecidos nessa legislação, esse também deve ser contado da data da publicação - considerada essa como a da publicação da Portaria MEC n. ${ }^{\circ}$ 345/2020, que retificou o texto da Portaria MEC n. 343/2020, ou seja, 19 de março de 2020. Outra intepretação possível - com os riscos dela decorrentes - seria considerar que esse prazo específico deveria ser contado da data em que a Instituição de Educação Superior (IES) iniciasse a substituição. Para as instituições que eventualmente decidiram tardiamente pela utilização da autorização estabelecida, essa interpretação sobra como única possibilidade.

Outro ponto a ser esclarecido no texto da Portaria MEC n. ${ }^{\circ}$ 343/2020 é o conteúdo do parágrafo $1^{\circ}$ do artigo $1^{\circ}$, que estabelece ser de "até trinta dias, prorrogáveis", o período de duração da autorização para substituição das aulas presencias por remotas. O texto desse dispositivo se manteve inalterado com a edição da Portaria MEC n. ${ }^{\circ}$ 345/2020. Entretanto, 
como a amplitude do conteúdo da Portaria original foi modificado, a contagem do prazo de trinta dias deve iniciar a partir da data da edição e publicação da norma retificadora - 19 de março de 2020 - como na situação anteriormente referida.

Dessa forma, o prazo original, de trinta dias, encerrou em 18 de abril de 2020. Em 15 de abril de 2020 foi editada a Portaria MEC n. 395 - publicada em 16 de abril de 2020 -, cujo conteúdo se restringiu a prorrogar por mais trinta dias o prazo estabelecido no parágrafo $1^{\mathrm{o}}$ do artigo $1^{\mathrm{o}}$ da Portaria original, passando, o prazo de validade da autorização para substituição das aulas presenciais por aulas remotas, para 18 de maio de 2020.

Relativamente à Medida Provisória n. ${ }^{\circ}$ 934/2020, embora tenha efeito imediato, na prática sua aplicação só se dará após o término da proibição de funcionamento das escolas e IES. Até isso ocorrer é provável que ela já tenha sido aprovada, com ou sem alterações. Além disso, há situação de regulamentação da forma de reposição integral da carga horária - sem o necessário cumprimento do número mínimo de dias letivos - que deve ainda ser objeto de ato específico do Conselho Nacional de Educação (CNE). ${ }^{2}$

\section{COMPETÊNCIA LEGISLATIVA}

Importante frisar que o Direito Provisório analisado neste artigo se refere exclusivamente à educação superior no âmbito do sistema federal de educação. Relativamente à essa matéria, o parágrafo $1^{\circ}$ do artigo $1^{\circ}$ da Portaria MEC n. ${ }^{\circ}$ 343/2020 contém, além do prazo já indicado e analisado na seção anterior, um outro elemento que precisa ser considerado, qual seja o da competência para definir novas prorrogações.

Relativamente à diretrizes e bases da educação nacional, a competência é privativa da União, nos termos do artigo 22, inciso XXIV, da Constituição Federal (CF). Quanto se trata, de forma mais genérica, de educação e de ensino, a competência é concorrente - União, Estados e Distrito Federal - conforme estabelece o artigo 24, inciso IX, da CF. Já quando cuida de proporcionar os meios de acesso à educação essa competência inclui ainda os municípios - é o que diz o artigo 23, inciso V, da CF.

2 Em 17 de abril de 2020 o CNE publicou Edital de Chamamento de Consulta Pública sobre o Parecer que trata da Reorganização dos Calendários Escolares e a realização de atividades pedagógicas não presenciais durante o período de Pandemia da COVID-19, com prazo para o envio de contribuições até 23 de abril do mesmo ano. A reunião deliberativa ocorreu no dia 28 de abril, mas até a data de fechamento deste artigo o Parecer não estava publicado na página do CNE. Além disso, para que tenha validade, deverá ainda ser homologado pelo Ministro da Educação. 
Especificamente no que diz respeito aos sistemas, de ensino, o caput do artigo 211 da CF estabelece que União, Estados, Distrito Federal e Municípios devem organizar seus sistemas de ensino em regime de colaboração. Já o parágrafo $1^{\circ}$ desse mesmo artigo, em sua parte inicial, estabelece, de forma literal: "A União organizará o sistema federal de ensino". Por exclusão, considerando o estabelecido nos parágrafos $2^{\circ}$ e $3^{\circ}$, ainda do artigo 211 da $\mathrm{CF}$, a atuação prioritária da União ocorrerá na educação superior.

Cabe ainda destacar, em termos de competência legislativa, que a Lei de Diretrizes e Bases da Educação Nacional (LDB), e seu artigo $9^{\circ}$ - incisos II, VII e VIII - define a competência da União para organizar o sistema federal de educação, editar normas gerais sobre pós-graduação e garantir processo nacional de avaliação da educação superior. E no inciso IX estabelece, expressamente, ser da União a competência para: “autorizar, reconhecer, credenciar, supervisionar e avaliar, respectivamente, os cursos das instituições de educação superior e os estabelecimentos do seu sistema de ensino".

No contexto das competências legislativas, considerando o exposto, é importante ressaltar que é da União a competência privativa das diretrizes e bases de todo o sistema educacional brasileiro. Também possui competência concorrente para legislar em matéria educacional e proporcionar os meios de acesso à educação, sendo, nesse sentido, responsável pelo estabelecimento das normas gerais nessas matérias. E, relativamente ao que importa para este texto, é a União competente para regrar, de forma exclusiva, o sistema federal de educação.

Essa clareza é importante para contextualizar e compreender a segunda parte do parágrafo $1^{\circ}$ do artigo $1^{\circ}$ da Portaria MEC n. ${ }^{\circ} 343 / 2020$, quando estabelece que o prazo é prorrogável, "a depender de orientação do Ministério da Saúde e dos órgãos de saúde estaduais, municipais e distrital". Esse texto normativo, contido em uma Portaria, não possui o condão - e nem o objetivo - de alterar competências legislativas contidas na Constituição e em leis federais.

O que ele indica é apenas que novas prorrogações, por ato do Ministério da Educação, levarão em consideração decisões tomadas, na área de saúde, pelos órgãos responsáveis. Isso significa que a orientação desses órgãos no sentido de manter, ou não, o isolamento social, será um elemento relevante na decisão MEC em prorrogar, ou não, o prazo estabelecido na Portaria. Não significa que esses órgãos - em especial os estaduais e municipais - possam, eles mesmos, prorrogar ou reduzir esse prazo. Também não significa 
que o MEC, necessariamente, prorrogará o prazo com base em decisões locais de manutenção de fechamento das instituições educacionais.

Há duas situações distintas que devem ser compreendidas: (a) a autorização para substituição de aulas presenciais por aulas remotas no âmbito do sistema federal de ensino, de um lado; (b) o estabelecimento de regras de isolamento social e de funcionamento das IES, de outro. Para a primeira situação a competência de regramento é exclusiva da União. Para a segunda, nos termos da recente decisão do $\mathrm{STF}^{3}$, a competência é concorrente, podendo os municípios, no seu âmbito territorial, estabelecerem normas mais restritivas - mas não menos restritivas - que os estados-membros e a União; e podendo, os estados-membros, no seu âmbito territorial, definirem restrições maiores do que a União - mas não menores.

Por que isso importa? Porque é possível ocorrer que um determinado município ou estado-membro estabeleça um prazo de proibição de funcionamento das IES, em seu território, mais longo do que o prazo de substituição estabelecido pela União. Embora as orientações dos órgãos de saúde, nos termos do parágrafo $1^{\circ}$ do $\operatorname{artigo~}^{\circ}$ da Portaria MEC $n .^{\circ}$ 343/2020, devam ser consideradas pela União, não há uma imposição no sentido de que obrigatoriamente o sejam.

Nessa situação, as IES integrantes do sistema federal de educação, sediadas em município ou estado-membro que tenha adota prazo de proibição maior, estarão impedidas de retomar suas atividades. E sem prorrogação da autorização para substituição das aulas presenciais por aulas remotas, por parte da União, estará igualmente impedida de utilizar essa alternativa.

É importante frisar, ainda, que nos termos do artigo $6^{\circ}$ da Lei n. ${ }^{\circ} 4.024 / 1961$ - com a redação que lhe foi dada pela Lei n. ${ }^{0}$ 9.131/1995 - o Ministério da Educação “exerce as atribuições do poder público federal em matéria de educação, cabendo-lhe formular $e$ avaliar a política nacional de educação, zelar pela qualidade do ensino e velar pelo cumprimento das leis que o regem".

No cumprimento dessas atribuições - conforme estabelece o mesmo artigo $6^{\circ}$, em seu parágrafo $1^{\circ}$ - conta com a colaboração do Conselho Nacional de Educação. O CNE, nos termos do artigo $7^{\circ}$, parágrafo $1^{\circ}$, da mesma lei, possui competência para- alíneas "b" e "f" "manifestar-se sobre questões que envolvam mais de um nível ou modalidade de ensino" e

3 BRASIL. STF. ADI n. ${ }^{\circ}$ 6341. Relator Ministro Marco Aurélio Mello. Brasília: Plenário, 15 abr. 2020. Disponível em: http://portal.stf.jus.br/processos/detalhe.asp?incidente=5880765. Acesso em: 22 abr. 2020. 
“analisar e emitir parecer sobre questões relativas à aplicação da legislação educacional que envolvam mais de um nível ou modalidade educacional, no que diz respeito à integração entre os diferentes níveis e modalidade de ensino". De forma mais geral - ainda nos termos do artigo $7^{\circ}$, parágrafo $1^{\circ}$, alínea "d" - o CNE possui competência para "emitir parecer sobre assuntos da área educacional”.

O Conselho Nacional de Educação possui duas Câmaras, a de Educação Básica (CEB) e a de Educação Superior (CES). Entre as competências da CES, definidas no artigo $9^{\circ}$, parágrafo $2^{\circ}$, da Lei n. ${ }^{\circ} 4.024 / 1961$ - com a redação que lhe foi dada pela Lei n. ${ }^{\circ}$ 9.131/1995 -, destacam-se, para os fins deste artigo, as das alíneas "h" e “i”, quais sejam: "analisar questões relativas à aplicação da legislação referente à educação superior" e “assessorar o Ministro de Estado da Educação [...] nos assuntos relativos à educação superior".

Com base nessas competências, em 17 de abril de 2020 o CNE publicou Edital de Chamamento de Consulta Pública sobre o Parecer que trata da Reorganização dos Calendários Escolares e a realização de atividades pedagógicas não presenciais durante o período de Pandemia da COVID-19, com prazo para o envio de contribuições até 23 de abril do mesmo ano. Com base nessa consulta e na legislação vigente, deverá o CNE elaborar, aprovar e encaminhar para o MEC parecer visando regulamentar as principais questões relativas à reorganização dos calendários escolares, em especial no que ser refere ao cumprimento de conteúdos e cargas e horárias e à dispensa de cumprimento do número mínimo de dias letivos anuais.

Há, ainda, no campo específico da competência normativa a situação da Coordenação de Aperfeiçoamento do Pessoal de Nível Superior (CAPES). Essa competência é definida pelo Estatuto da CAPES, aprovado pelo Decreto n. ${ }^{\circ}$ 8.977/2017. Foi com base no artigo 26 desse Estatuto - que estabelece as atribuições dos dirigentes da CAPES - que foi editada a Portaria que orienta as IES a suspenderem as bancas presenciais e a realizarem-nas utilizando tecnologias de comunicação à distância.

\section{AbRANGÊNCIA DA SUbSTITUIÇÃo DE AULAS PRESENCIAIS POR AULAS REMOTAS}


O conjunto de documentos formado pelas Portarias MEC n. ${ }^{\circ} 343 / 2020$, n. ${ }^{\circ} 345 / 2020$

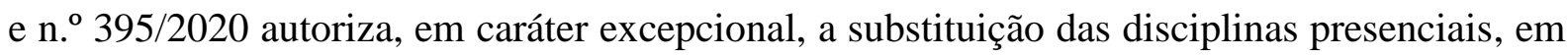
andamento, por aulas que utilizem meios e tecnologias de informação e comunicação, denominadas, neste trabalho, de aulas remotas.

Essa substituição, conforme indica, literalmente, o artigo $1^{\circ}$ da Portaria MEC n. ${ }^{o}$ 343/2020 - com a redação que lhe foi atribuída pela da Portaria MEC n. ${ }^{\circ}$ 345/2020 - só é aplicável às disciplinas "em andamento" na data da edição na norma. Disciplinas previstas como presenciais no Projeto Pedagógico do Curso (PPC) e iniciadas posteriormente à data da publicação da Portaria retificadora - 19 de março de 2020 - estão excluídas dessa possibilidade de substituição.

A análise do texto da Portaria MEC n. ${ }^{\circ}$ 343/2020 - com as modificações introduzidas pelas Portarias MEC n. ${ }^{\circ}$ 345/2020 e n. ${ }^{o}$ 395/2020 - indica que sua aplicação é genérica, para todos os cursos superiores do sistema federal de educação em funcionamento regular. Isso inclui a Pós-Graduação. Parece ser essa a melhor interpretação do texto do $\operatorname{artigo~} 1^{\circ}$ da Portaria, em sua versão final:

Art. $1^{\circ}$ Fica autorizada, em caráter excepcional, a substituição das disciplinas presenciais, em andamento, por aulas que utilizem meios e tecnologias de informação e comunicação, por instituição de educação superior integrante do sistema federal de ensino, de que trata o art. $2^{\circ}$ do Decreto n. ${ }^{\circ} 9.235$, de 15 de dezembro de 2017.

O texto legal não faz referência expressa a qualquer espécie de curso. Na sua versão original - na qual havia referência à limitação vigente na legislação em vigor - seria aceitável uma leitura restritiva, considerando que a legislação vigente nessa matéria - Portaria MEC n. ${ }^{\circ}$ 2.117/2019 - refere-se expressamente aos cursos de graduação. A retirada dessa expressão, elimina o limite percentual de $40 \%$ previsto na Portaria MEC n. ${ }^{\circ} 2.117 / 2019$, bem como exclui uma possível restrição, aos cursos de graduação, da possibilidade de substituição das aulas presenciais por aulas remotas.

A redação inicial do artigo $1^{\circ}$ da Portaria MEC n. ${ }^{\circ} 343 / 2020$ - editada em 17 e publicado em 18 de março de 2020 - continha, relativamente à autorização de substituição das aulas presenciais por aulas remotas, uma indicação restritiva, contida na expressão "nos limites estabelecidos pela legislação em vigor". Esse trecho específico do texto normativo foi suprimido pela Portaria MEC n. ${ }^{\circ}$ 345/2020 - editada e publicada em 19 de março de 2020. 
Em termos de interpretação jurídica é necessário reconhecer que essa supressão possui significado. Não quisesse o legislador alterar o alcance na norma, teria mantido o texto normativo inalterado, sem a exclusão do trecho que remetia à outra legislação já vigente. Assim, a interpretação que impõe é que a substituição - de aulas presencias por aulas remotas - tem como limitação apenas o período temporal estabelecido na Portaria e não as limitações, em percentuais, previstas na Portaria n. ${ }^{\circ}$ MEC 2.117/2019 - legislação em vigor relativamente à utilização parcial de Ensino à Distância $(\mathrm{EaD})$ em cursos presenciais.

Essa Portaria estabelece o limite de $40 \%$ da carga horária total do curso para a oferta de disciplinas, na modalidade $\mathrm{EaD}$, em cursos de graduação presenciais, não contendo nenhuma referência expressa à sua utilização na pós-graduação presencial. A Resolução CNE/CES n. ${ }^{\circ}$ 1/2018, que trata da Pós-Graduação Lato Sensu - na modalidade especialização -, contém a previsão de cursos $100 \% \mathrm{EaD}$, oferecidos por instituições devidamente credenciadas, mas não contém autorização para que IES não credenciadas para essa modalidade possam oferecer cursos híbridos.

Relativamente à Pós-Graduação Stricto Sensu - mestrados e doutorados - é possível, por via interpretativa, aplicar o percentual definido na Portaria MEC n. ${ }^{\circ}$ 2.117/2019. A Portaria CAPES n. ${ }^{\circ}$ 275/2018 estabelece que se aplicam aos cursos presenciais stricto sensu, "no que couber", as mesmas regras aplicáveis à graduação, relativamente às atividades à distância. Ela refere expressamente a aplicação, nessa matéria, da Portaria MEC n. ${ }^{\text {o }}$ 1.134/2016; essa Portaria foi substituída pela Portaria MEC n. ${ }^{\circ}$ 1.428/2018; e essa pela Portaria MEC n. ${ }^{\circ}$ 2.117/2019. Salvo interpretação mais adequada, na expressão "no que couber" está incluído o limite percentual de atividades em EaD.

É importante considerar, nessa matéria, que o objetivo da flexibilização legal é permitir que o processo de ensino-aprendizagem tenha prosseguimento durante o período da pandemia. Limitar essa flexibilização, no percentual já autorizado em legislação específica $40 \%$ do total da carga horária do curso -, excluiria do alcance da norma as instituições que já utilizam esse percentual máximo na organização de seus cursos. Da mesma forma, excluir dessa flexibilização a pós-graduação, seria impor um grande prejuízo aos milhares de pósgraduandos de todo o país que teriam de interromper seus estudos. Assim, a atribuição de sentido amplo ao texto legal, é a que melhor coaduna com seus objetivos.

Retomando a Portaria MEC n. ${ }^{\circ} 343 / 2020$, ela, no parágrafo $2^{\circ}$ do artigo $1^{\circ}$, atribuí às IES autonomia na definição das disciplinas nas quais ocorrerá a substituição das aulas 
presenciais por aulas remotas. Da mesma forma, é de responsabilidade das IES a "disponibilização de ferramentas aos alunos que permitam o acompanhamento dos conteúdos ofertados bem como a realização de avaliações" durante o período em que essa substituição ocorrer. Isso implica que as escolhas recaem integralmente sobre as IES, no exercício de sua autonomia. Da mesma forma, as responsabilidades pelas escolhas adotadas.

Optar, por exemplo, pela substituição das aulas presenciais, por aulas remotas síncronas, utilizando programas de videoconferência, significa manter calendários e horários letivos, pagamentos de horas-aulas integrais aos docentes - que estarão cumprindo exatamente os mesmos horários letivos que cumpririam nas aulas presenciais - e cobrança integral de mensalidades. A adoção de modelos assíncronos, como comumente ocorre nos cursos que utilizam Educação à Distância $(\mathrm{EaD})$, terá outra espécie de consequência. É importante lembrar que se está falando de substituição temporária de atividades presenciais em cursos originariamente presenciais.

\section{SUSPENSÃO DAS ATIVIDADES ACADÊMICAS COMO ALTERNATIVA E SUAS CONSEQUÊNCIAS}

A Portaria MEC n. ${ }^{\circ}$ 343/2020 contém, como alternativa à substituição das aulas presenciais por aulas remotas, a suspensão, por parte das IES, das suas atividades acadêmicas. É o que estabelece o seu artigo $2^{\circ}$, in verbis:

Art. $2^{\circ}$ Alternativamente à autorização de que trata o art. $1^{\circ}$, as instituições de educação superior poderão suspender as atividades acadêmicas presenciais pelo mesmo prazo.

$\S 1^{\circ}$ As atividades acadêmicas suspensas deverão ser integralmente repostas para fins de cumprimento dos dias letivos e horas-aulas estabelecidos na legislação em vigor.

$\S 2^{\circ}$ As instituições poderão, ainda, alterar o calendário de férias, desde que cumpram os dias letivos e horas-aula estabelecidos na legislação em vigor.

Esse dispositivo estabelece que as IES, no âmbito de sua autonomia, poderão escolher, alternativamente à substituição das aulas presencias por aulas remotas, pela suspensão das atividades acadêmicas presenciais, pelo mesmo prazo - até 18 de maio de 2020, considerando os trinta dias iniciais e os trinta dias da prorrogação já adotada.

Ressalte-se que o prazo acima indicado se refere àquele autorizado pela União, dentro do qual a instituição, por decisão sua, pode optar por não substituir as aulas presenciais 
por aulas remotas e sim por suspender suas atividades - é uma escolha que lhe foi facultada dentro desse período específico.

Situação diversa ocorrerá se houver ato proibitivo de funcionamento - por decisão municipal ou estadual - que se extensa além dessa data, sem nova prorrogação, por parte da União, para a substituição das aulas presenciais por aulas remotas. Nessa situação as aulas presenciais serão suspensas, independentemente da vontade da IES, a substituição não poderá ocorrer, por ausência de autorização de quem tem a competência legal para fazê-lo.

Nesse contexto, guardam importância algumas definições constantes de ambos os parágrafos do artigo $2^{\circ}$ da Portaria MEC n..$^{\circ}$ 343/2020: a necessidade de reposição integral (a) dos dias letivos estabelecidos na Lei de Diretrizes e Bases (LDB) e (b) das horas-aula definidas nas Diretrizes Curriculares Nacionais (DCNs) e no PPC.

Destaque-se, ainda, que o parágrafo $2^{\circ}$, do transcrito artigo $2^{\circ}$ da Portaria MEC n. ${ }^{\circ}$ 343/2020, permite, como forma de reposição, a alteração do calendário de férias. Nessa situação a IES anteciparia as férias de seus professores, funcionários e alunos, repondo as atividades nas datas originariamente a elas destinadas.

Relativamente às cargas horárias é importante frisar que o número de horas que deverá ser obrigatoriamente cumprindo é o que está estabelecido no PPC, mesmo que superior ao número mínimo de horas definido nas respectivas DCNs. Relativamente ao número de dias letivos anuais, estão eles estabelecidos no artigo 47 da LDB, em número de $200^{4}$. Há, entretanto, em tramitação no Congresso Nacional, a Medida Provisória n 934/2020 (MP n. ${ }^{\text {o }}$ 934/2020), que visa permitir, em caráter excepcional, que em 2020 esse número não precise ser cumprido. Seu texto, relativamente à educação superior, prescreve:

Art. $2^{\circ}$ As instituições de educação superior ficam dispensadas, em caráter excepcional, da obrigatoriedade de observância ao mínimo de dias de efetivo trabalho acadêmico, nos termos do disposto no caput e no $\S 3^{\circ}$ do art. 47 da Lei n. ${ }^{\circ}$ 9.394, de 1996, para o ano letivo afetado pelas medidas para enfrentamento da situação de emergência de saúde pública de que trata a Lei n. $^{\circ} 13.979$, de 2020, observadas as normas a serem editadas pelos respectivos sistemas de ensino.

Parágrafo único. Na hipótese de que trata o caput, a instituição de educação superior poderá abreviar a duração dos cursos de Medicina, Farmácia, Enfermagem e Fisioterapia, desde que o aluno, observadas as regras a serem editadas pelo respectivo sistema de ensino, cumpra, no mínimo:

4 LDB - Art. 47. Na educação superior, o ano letivo regular, independente do ano civil, tem, no mínimo, duzentos dias de trabalho acadêmico efetivo, excluído o tempo reservado aos exames finais, quando houver. 
I - setenta e cinco por cento da carga horária do internato do curso de medicina; ou

II - setenta e cinco por cento da carga horária do estágio curricular obrigatório dos cursos de enfermagem, farmácia e fisioterapia.

O caput do artigo $2^{\circ}$ da MP n. ${ }^{\circ}$ 934/2020 dispensa expressamente as IES do cumprimento do número mínimo de dias letivos, mas não contém qualquer referência expressa relativamente ao cumprimento da carga horária. Já a sua leitura, em conjunto com o parágrafo único e seus incisos, parece indicar a obrigatoriedade do cumprimento do número de horas previstas para o curso.

O parágrafo único - do artigo $2^{\circ}$ - e seus incisos contêm uma exceção que permite, especificamente para os cursos da área de saúde, uma redução de carga horária. Nesse sentido, indicam que a supressão de um percentual ou quantidade de horas depende de disposição expressa. Em sentido inverso, não havendo disposição expressa, impõe-se a reposição.

É possível, entretanto, que norma específica venha a autorizar também essa redução - a parte final do texto do parágrafo único estabelece que a dispensa de cumprimento dos dias letivos será realizada "observadas as normas a serem editadas pelos respectivos sistemas de ensino". Não havendo nenhuma nova norma oriunda dos órgãos competentes, que para o sistema federal de ensino são o MEC e CNE, mantém-se a obrigatoriedade estabelecida na parte final dos parágrafos $1^{\circ}$ e $2^{\circ}$ do artigo $2^{\circ}$ da Portaria MEC n. ${ }^{\circ} 343 / 2020$ - cumprimento da carga horária estabelecida na legislação em vigor.

Já o disposto no parágrafo único e seus parágrafos, do artigo $2^{\circ}$ da MP n. ${ }^{\circ} 934 / 2020$ a possibilidade de abreviar o tempo de duração e, dessa forma, também a carga horária dos cursos de medicina, enfermagem, fisioterapia e farmácia, - é uma especificidade destinada a inserir no mercado de trabalho, de forma antecipada, novos profissionais da área de saúde. Essa antecipação da formatura fica, entretanto, a critério de cada IES. A norma é expressa no sentido que a IES “poderá abreviar a duração cursos”. Não contém, nesse sentido, um direito subjetivo do aluno à colação antecipada de grau.

\section{ESPECIFICIDADES DAS PRÁTICAS PROFISSIONAIS ${ }^{5}$}

5 Essa restrição foi bastante reduzida com a edição da Portaria MEC n. ${ }^{\circ}$ 544/2020. Como o artigo foi aprovado para apresentação no GT Pesquisa e Educação Jurídica - do I Encontro Virtual do CONPEDI - em versão anterior à essa alteração, a opção adotada para atualizá-lo na versão publicada foi inserir um apêndice com as principais modificações - sobre elas ver o Apêndice A deste artigo. 
Ainda no âmbito da Portaria MEC n. ${ }^{\circ}$ 343/2020 - com modificações introduzidas pela Portaria MEC n. ${ }^{\circ}$ 345/2020 - há o tratamento diferenciado dado às práticas profissionais. Essa matéria é objeto do artigo $1^{\circ}$, em seus parágrafos $3^{\circ}$ e $4^{\circ}$. O parágrafo $3^{\circ}$ proíbe expressamente a substituição de aulas presenciais por aulas remotas nas "práticas profissionais de estágios e de laboratório". Já o parágrafo $4^{\circ}$ estabelece que, no Curso de Medicina, essa substituição apenas poderá ocorrer nas "disciplinas teóricas-cognitivas do primeiro ao quarto ano do curso".

O dispositivo que trata especificamente do Curso de Medicina não oferece maior margem de interpretação: as disciplinas teóricas podem ser substituídas e o internato - que ocorre nos dois últimos anos - não pode. A dúvida maior reside no alcance do conteúdo do parágrafo $3^{\circ}$. Esse dispositivo veda, expressamente a substituição - grifei - das práticas profissionais - realizadas em laboratórios ou através de estágios - por atividades remotas. Por que grifar a expressão substituição? Porque naquelas atividades práticas que já ocorriam, naturalmente, de forma remota, não há substituição - e, portanto, elas podem e devem ser mantidas. Não se pode atribuir à essa proibição um alcance maior do que ela contém.

Essa situação pode ser melhor compreendida olhando para um curso e situação específicos. Nos Cursos de Direito existe o Núcleo de Práticas Jurídicas (NPJ). No NPJ há atividades de prática profissional que são presencias, como o atendimento de partes que ocorre nos serviços de assistência jurídica mantidos pelas respectivas IES. Esse atendimento, sendo previsto no PPC e regrado no Regulamento do NPJ como presencial, não poderá ser substituído por atividade remota. Mas, em sentido diverso, se o PPC - e a devida regulamentação - estabelecem um serviço de atendimento virtual, já em funcionamento antes da pandemia e da edição da Portaria MEC n. ${ }^{\circ}$ 343/2020, nenhum impedimento há no sentido de que essa atividade de aprendizado de práticas profissionais se mantenha. Da mesma forma, a proibição não alcança a prática dos atos que integram o Processo Eletrônico que, pela sua própria natureza, são realizados de forma remota.

\section{BANCAS UTILIZANDO TECNOLOGIAS DE COMUNICAÇÃO À DISTÂNCIA}

Na seara da Pós-Graduação Stricto Sensu é importante destacar, ainda, a Portaria CAPES n. ${ }^{\circ}$ 36/2020. Essa Portaria contém um conjunto de recomendações, no âmbito dos 
programas de concessão de bolsas da CAPES, que pode ser apresentado da seguinte forma: (a) suspensão, por sessenta dias - até 19 de maio de 2020 - dos prazos de defesa presencial de dissertações e teses; (b) possibilidade dessas defesas ocorrerem com a utilização de tecnologias de comunicação à distância, quando admissíveis pelos respectivos Programas e nos termos da sua regulamentação pelo MEC; (c) recomendação, às IES que não possuem previsão de defesas não presenciais em seus Programas, que adotem, em caráter excepcional, as providências necessárias para viabilizá-las. Em síntese, a CAPES recomenda (a) a suspensão das bancas presenciais e (b) a realização de bancas por videoconferência pelo período de sessenta dias, contados da publicação da Portaria - 20 de março de 2020.

\section{CONCUSÃO}

A legislação temporária, editada para dar solução aos problemas ocorridos no contexto educacional, em especial no âmbito da educação superior, decorrentes da Pandemia da Covid-19, apresenta às IES, de forma resumida, duas possibilidades de encaminhamentos, aplicáveis, de forma geral, a todos os cursos e níveis.

A primeira é no sentido da substituição das aulas presenciais por aulas remotas, mantidos os calendários e horários regulares dos cursos. Na pós-graduação essa alternativa também foi sugerida, pela CAPES, aos programas de pós-graduação stricto sensu, para a realização das bancas de Mestrado e Doutorado, com a utilização de tecnologias de comunicação à distância.

Essa alternativa tem, na legislação editada, apenas uma restrição: ela não se aplica às práticas profissionais realizadas em laboratórios ou através de estágios ${ }^{6} \mathrm{E}$, no caso específico do Curso de Medicina, não se aplica ao período de internato, que ocorre nos dois últimos anos. De outro lado, permite a formatura antecipada dos alunos de Medicina, Enfermagem, Fisioterapia e Farmácia que já tiverem concluído 75\% da sua formação prático-profissional.

A segunda possibilidade disponibilizada é a suspensão do processo de ensinoaprendizagem durante o período da Pandemia; permita, nesse caso, a antecipação dos períodos de férias. Adotada essa opção, quando do retorno das atividades as IES - e seus cursos - terão de reorganizar horários e calendários. A legislação, na forma editada, permite o

6 Essa restrição foi bastante reduzida com a edição da Portaria MEC n. ${ }^{0}$ 544/2020. Sobre esse tema ver o Apêndice A deste artigo. 
não cumprimento dos dias letivos mínimos definidos pela $\mathrm{LDB}$, mas não permite o descumprimento das cargas horárias e conteúdos.

A suspensão das aulas e atividades pelas instituições gera situações bem mais complexas em termos de encaminhamentos para o futuro. Embora o calendário possa ser encurtado - em termos de dias de atividades - para fechar o ano letivo, a necessidade de cumprimento das cargas horárias e conteúdos impõe que, de alguma forma, sejam previstas e realizadas atividades compensatórias, quer sejam presenciais, quer sejam através de EaD.

\section{REFERÊNCIAS}

BRASIL. Constituição da República Federativa do Brasil de 1988. Disponível em: http://www.planalto.gov.br/ccivil_03/constituicao/constituicao.htm. Acesso em: 27 jan. 2019.

BRASIL. Lei n. ${ }^{\circ}$ 4.024, de 20 de abril de 1961. [Cria o CNE e estabelece sua estrutura e competências]. Disponível em: http://www.planalto.gov.br/ccivil_03/LEIS/L4024.htm. Acesso em: 27 jan. 2019.

BRASIL. Lei n. ${ }^{\circ}$ 9.131, de 24 de novembro de 1995. Altera dispositivos da Lei n. ${ }^{\circ}$ 4.024, de 20 de dezembro de 1961... [cria o CNE]. Disponível em: Disponível em:

http://www.planalto.gov.br/ccivil_03/LEIS/L9131.htm. Acesso em: 27 jan. 2019

BRASIL. Lei n. 9.394/1996. Estabelece as diretrizes e bases da educação nacional.

Disponível em: http://www.planalto.gov.br/ccivil_03/Leis/L9394.htm. Acesso em: 27 jan. 2019.

BRASIL. Presidência da República. Estatuto da Coordenação de Aperfeiçoamento de Pessoal de Nível Superior - CAPES. Aprovado pela Decreto n. ${ }^{\circ} 8.977$, de 30 de janeiro de 2017. Disponível em: http://www.planalto.gov.br/ccivil_03/_ato20152018/2017/decreto/D8977.htm. Acesso em: 22 abr. 2020.

BRASIL. CAPES. Portaria n. ${ }^{\mathbf{3}}$ 36, de 19 de março de 2020. Dispõe sobre a suspensão excepcional dos prazos para defesa de dissertação ou tese no âmbito dos programas de concessão de bolsas da Capes. Disponível em: http://www.in.gov.br/en/web/dou/-/portaria-n36-de-19-de-marco-de-2020-249026197. Acesso em: 22 abr. 2020.

BRASIL. MEC. Portaria n. ${ }^{\circ}$ 343, de 17 de março de 2020. Dispõe sobre a substituição das aulas presenciais por aulas em meios digitais enquanto durar a situação de pandemia do Novo Coronavírus - COVID-19. Disponível em: http://www.in.gov.br/en/web/dou/-/portaria-n-343de-17-de-marco-de-2020-248564376. Acesso em: 22 abr. 2020.

BRASIL. MEC. Portaria n. ${ }^{\circ}$ 345, de 19 de março de 2020. Altera a Portaria MEC n. ${ }^{\mathbf{3}}$ 343, de 17 de março de 2020. Disponível em: http://www.in.gov.br/en/web/dou/-/portaria-n-345-de19-de-marco-de-2020-248881422. Acesso em: 22 abr. 2020. 
BRASIL. MEC. Portaria n. ${ }^{\circ}$ 395, de 15 de abril de 2020. Prorroga o prazo previsto no $\S 1^{\circ}$ do art. $1^{\circ}$ da Portaria n. ${ }^{\circ} 343$, de 17 de março de 2020. Disponível em:

http://pesquisa.in.gov.br/imprensa/jsp/visualiza/index.jsp?data=16/04/2020\&jornal=515\&pagi na=61. Acesso em: 22 abr. 2020.

BRASIL. STF. ADI n. ${ }^{\circ}$ 6341. Relator Ministro Marco Aurélio Mello. Brasília: Plenário, 15 abr. 2020. Disponível em: http://portal.stf.jus.br/processos/detalhe.asp?incidente=5880765. Acesso em: 22 abr. 2020.

RODRIGUES, Horácio Wanderlei. Direito Educacional em tempos de pandemia: normas de caráter temporário. Revista Consultor Jurídico - ConJur, 23 abr. 2020. Disponível em: https://www.conjur.com.br/2020-abr-23/direito-pos-graduacao-direito-educacional-tempospandemia-normas-temporarias?fbclid=IwAR2XmtGJqi2TkNqGRCE1_9EqqmE2_qw8wI6dgBJBymf3NSRB_4zHEU96Cc

\section{APÊNDICE A}

\section{A PORTARIA MEC N. 544/2020 E AS ATIVIDADES DE FORMAÇÃO PRÁTICA}

O objeto deste apêndice são as atividades de formação prático-profissional existentes em todos os cursos superiores e sua situação frente à Portaria MEC n. ${ }^{0}$ 544/2020 ${ }^{7}$ e ao Parecer CNE/CP n. ${ }^{\circ} 5 / 2020^{8}$, editados durante a Pandemia da Covid-10, tratando da substituição do ensino presencial por ensino remoto. Esse tema tem sido alvo de grandes dúvidas por parte das Instituições de Educação Superior (IES) e buscar-se-á, aqui, esclarecê-las da forma mais didática possível.

A Portaria MEC n. ${ }^{\circ}$ 544/2020 - como ocorria na Portaria MEC n. ${ }^{\circ}$ 343/2020, com as modificações introduzidas pela Portaria MEC n. 345/2020 - diferencia formação prática de formação teórico-cognitiva para fins de aplicação, pelas IES, da substituição de atividades presenciais por atividades remotas. A nova legislação, entretanto, é bem mais flexível,

7 BRASIL. MEC. Portaria $\mathbf{n}^{\mathbf{0}} \mathbf{5 4 4}$, de 16 de junho de 2020. Dispõe sobre a substituição das aulas presenciais por aulas em meios digitais, enquanto durar a situação de pandemia do novo conoravírus - Covid-19, e revoga as Portarias MEC n⿳ 343, de 17 de março de 2020, nº 345, de 19 de março de 2020, e no 473, de 12 de maio de 2020. Disponível em: http://www.in.gov.br/web/dou/-/portaria-n-544-de-16-de-junho-de-2020261924872. Acesso em: 21 jun. 2020.

8 BRASIL. CNE. Parecer CNE/CP no 5/2020. Reorganização do Calendário Escolar e da possibilidade de cômputo de atividades não presenciais para fins de cumprimento da carga horária mínima anual, em razão da pandemia da COVID-19. Disponível em: http://portal.mec.gov.br/conselho-nacional-de-educacao/atosnormativos--sumulas-pareceres-e-resolucoes/33371-cne-conselho-nacional-de-educacao/85201-parecer-cp2020. Acesso em: 1 jun. 2020. 
ampliando muito as possibilidades no âmbito das práticas realizadas através de estágios ou em laboratórios. Essa matéria é objeto do artigo $1^{\circ}$, em seus parágrafos $3^{\circ}, 4^{\circ}$ e $5^{\circ}$.

$\S 3^{\circ}$ No que se refere às práticas profissionais de estágios ou às práticas que exijam laboratórios especializados, a aplicação da substituição de que trata o caput deve obedecer às Diretrizes Nacionais Curriculares aprovadas pelo Conselho Nacional de Educação - CNE, ficando vedada a substituição daqueles cursos que não estejam disciplinados pelo CNE. (grifei).

$\S 4^{\circ}$ A aplicação da substituição de práticas profissionais ou de práticas que exijam laboratórios especializados, de que trata o $\S 3^{\circ}$, deve constar de planos de trabalhos específicos, aprovados, no âmbito institucional, pelos colegiados de cursos e apensados ao projeto pedagógico do curso. (grifei)

$\S 5^{\circ}$ Especificamente para o curso de Medicina, fica autorizada a substituição de que trata o caput apenas às disciplinas teórico-cognitivas do primeiro ao quarto ano do curso e ao internato, conforme disciplinado pelo CNE.

Inicialmente deve-se destacar que a possibilidade de substituição das práticas formativas - que ocorrem através de estágios ou em laboratórios - por aulas e atividades remotas aplica-se, exclusivamente, aos cursos superiores que possuam DCNs devidamente aprovadas e editadas pelo CNE. Cursos novos e experimentais, ainda sem DCNs definidas pelo CNE, estão expressamente proibidos de utilizarem a inovação normativa contida na Portaria MEC n. ${ }^{\circ}$ 544/2020.

O dispositivo que trata especificamente do Curso de Medicina, no que se refere às disciplinas teórico-cognitivas oferecidas do primeiro ao quarto ano, não oferece maior margem de interpretação: elas podem ser substituídas por aulas e atividades remotas. Quanto ao internato - que ocorre nos dois últimos anos do curso -, o texto normativo, interpretado de forma gramatical, sem considerar a restrição contida no final do texto do parágrafo (“conforme disciplinado pelo CNE"), pode dar margem à substituição mais ampla, de atividades presenciais por atividades remotas, do que a pretendida.

As manifestações públicas de representantes da Secretaria de Regulação e Supervisão da Educação Superior (SERES) e do Presidente do CNE indicam que a possibilidade de substituição, de atividades presenciais por atividades remotas, no âmbito do internato, está restrita à parcela de aulas e atividades teórico-cognitivas contida nesse período do curso. E essa parcela está limitada, nos termos do parágrafo $6^{\circ}$ do artigo 24 da Resolução CNE/CES n. ${ }^{\circ}$ 3/2014 - DCNs do Curso de Medicina -, em cada uma das áreas de estágio definidas nas DCNs, em no máximo $20 \%$ da respectiva carga horária. 
A dúvida que permanece, mesmo com a edição a nova Portaria, reside no alcance do conteúdo do parágrafo $3^{\circ}$, excetuada a parte final. Este dispositivo - em sentido contrário ao que dispunha a Portaria revogada - autoriza, expressamente, a "substituição" das "práticas profissionais de estágios" e das "práticas que exijam laboratórios especializados" por atividades remotas.

Destaque-se, de início, a utilização da expressão "substituição". A sua presença no texto normativo indica que naquelas atividades práticas que já ocorriam, naturalmente, de forma remota, não há substituição. Portanto, elas podem e devem ser mantidas exatamente na forma em que já vinham sendo realizadas.

Também merece referência, desde logo, que as práticas simuladas não estão incluídas no contexto normativo do parágrafo $3^{\circ}$ do artigo $1^{\circ}$ da Portaria MEC n. $^{\circ}$ 444/2020. Ao fazer referência expressa às "práticas profissionais de estágios ou às práticas que exijam laboratórios especializados", esse dispositivo restringe a sua aplicação às práticas reais. Não estando, as práticas simuladas, contidas no âmbito da norma restritiva, a elas aplica-se a regra geral do caput, qual seja, a da possibilidade ampla de substituição.

Há as atividades práticas simuladas, nas quais o aluno não age no mundo real, mas em situações de simulação da realidade. Nos Cursos de Direito, isso ocorre, por exemplo, nos júris simulados, bem como em todas as demais situações de processos simulados nos quais os alunos elaboram documentos e atuam em casos escolhidos ou elaborados para essa finalidade - denominados de casos de ensino. Relativamente a essa modalidade de atividades de formação prática, não há qualquer proibição de substituição por atividades remotas.

De outro lado, há as atividades práticas reais --sobre as quais incide a proibição de substituição -, nestas os alunos interagem com situações da vida profissional efetivamente existentes e contemporâneas. Tais atividades podem ser estágios - quando cumprirem todas as exigências da Lei n. ${ }^{\circ}$ 11.788/2008 - ou outras atividades reais voltadas à formação profissional, mas não enquadradas nessa categoria jurídica específica, como aquelas que ocorrem em laboratórios das próprias IES.

Nos termos do artigo $1^{\circ}$ da Lei de Estágios - Lei n. ${ }^{\circ} 11.788 / 2008$ : “Estágio é ato educativo escolar supervisionado, desenvolvido no ambiente de trabalho, que visa à preparação para o trabalho produtivo de educandos que estejam frequentando o ensino regular em instituições de educação superior [...]". 
Esse texto legal traz, para elucidação da matéria, outro elemento decisivo: "desenvolvido no ambiente de trabalho". Se o estágio realiza-se em ambiente digital de trabalho - como no home office definido pela concedente e nas situações de teletrabalho - e cumpre, integralmente, as demais exigências contidas na legislação aplicável, não há nenhuma necessidade de sua substituição. Essas atividades podem ser consideradas e contabilizadas como carga horário de estágio regular, nos termos estabelecidos no Projeto Pedagógico do Curso (PPC).

Para a área de Direito, temos estágio supervisionado nas situações em que o aluno atua, a título de exemplos, junto a escritório de advocacia, departamento jurídico de empresa, Defensoria Pública, Ministério Público ou Poder Judiciário - parte concedente. Também ocorre quando o aluno estagiar no departamento jurídico da IES, por ele supervisionado, e orientado por professor do Curso.

Já as atividades junto ao Serviço de Assistência Jurídica do próprio Curso de Direito não configuram necessariamente estágio - pelo menos em sentido estrito. Nele não há termo de compromisso e nem parte concedente. Há laboratório de práticas reais, pertencente à estrutura do próprio Curso, desenvolvidas através de atividades de extensão - prestação de serviço à comunidade.

Relativamente aos "planos de trabalhos específicos", necessários para a "aplicação da substituição de práticas profissionais ou de práticas que exijam laboratório especializados" - parágrafo $3^{\circ}$ do artigo $1^{\circ}$ da Portaria MEC n. ${ }^{\circ}$ 544/2020 -, as situações em que se fazem necessários podem ser melhor identificadas olhando para a realidade de um curso em particular. Importante lembrar, antes de avançar, que esses planos devem ser aprovados pelos colegiados competentes no âmbito da respectiva IES e apensados aos PPCs ou seja, esses planos constituem alteração temporária dos Projetos Pedagógicos dos Cursos.

Nos Cursos de Direito, existe o Núcleo de Práticas Jurídicas (NPJ), no qual há atividades de formação prática que são presencias, como o atendimento de partes que ocorre nos Serviços de Assistência Jurídica mantidos pelas respectivas IES. Esse atendimento, sendo previsto no PPC e regrado no Regulamento do NPJ como presencial, só poderá ser substituído por atividade remota ou simulada - em parte - mediante expressa alteração desses documentos.

Em sentido diverso, se o PPC e a devida regulamentação estabelecem um serviço de atendimento digital, já em funcionamento antes da pandemia e da edição da Portaria MEC n. ${ }^{\circ}$ 
544/2020, a alteração é dispensável. Da mesma forma, a necessidade de alteração do PPC não alcança a prática dos atos que, pela sua própria natureza, são realizados de forma remota, tais como: acompanhamento de processos, audiências por videoconferência e todos os demais realizados, no processo eletrônico, através de tecnologias de comunicação e de informação.

Também não há necessidade de alterar o PPC nos casos em que o ambiente de trabalho já ocorria em home office ou por meio de teletrabalho, bem como nas situações em que ele foi transferido, pela concedente, para esses ambientes. É recomendável, entretanto, a assinatura de um aditivo ao termo de estágio para incluir essa situação, em especial para adequar o plano de trabalho do estagiário, se ela já não estava prevista no texto original.

Mantidos os atuais termos da legislação criada para o período de duração da pandemia da Covi-19, e pensando na necessária reposição das práticas reais que foram suspensas até a edição da Portaria MEC n. ${ }^{\circ}$ 544/2020, é fundamental rever, mesmo que de forma transitória, os PPCs dos cursos superiores para implementação de modificações que incluam atividades remotas - EaD síncrono ou assíncrono - no início do próximo período letivo.

Além da exigência prevista no parágrafo $3^{\circ}$ do artigo $1^{\circ}$ da Portaria MEC n. ${ }^{\circ}$ 544/2020, a Portaria MEC n. ${ }^{\circ}$ 2.117/2019 estabelece, no parágrafo único do seu artigo $5^{\circ}$, que: "Para os cursos em funcionamento, a introdução de carga horária a distância deve ocorrer em período letivo posterior à alteração do PPC". Esta alteração deve ser realizada, visando garantir segurança jurídica, ainda no atual período letivo, e permitirá:

a) tornar expresso o reconhecimento das situações de home office, teletrabalho e outras formas de atividades remotas, como atividades de formação prática válidas - quer como estágios, quer como laboratórios (em sentido amplo, incluindo todas as atividades reais de formação profissional não enquadradas na Lei de Estágios);

b) permitir a substituição de parte das atividades de formação prática real por atividades de formação prática simulada, respeitados eventuais limites mínimos e/ou máximos estabelecidos nas respectivas DCNs e na legislação educacional aplicável;

c) construir, como sugerido no Parecer CNE/CES n. ${ }^{\circ}$ 5/2020, projetos de extensão voltados à formação prático-profissional a serem desenvolvidos à distância e que 
possam ser oferecidos aos alunos como forma de cumprimento das cargas horárias de atividades reais de formação prática;

d) possibilitar - adotadas as propostas das letras "a", "b" e "c" - a reposição da carga horária de atividades de formação prática não cumprida no primeiro período letivo do ano de 2020.

As IES que não tomarem as indispensáveis providências, no âmbito interno, modificando seus PPCs e demais regulamentações relativas às atividades de formação prática - visando cumprir especificamente as exigências legais em termos de preparação práticoprofissional -, estarão deixando de introduzir as adaptações necessárias para que seus alunos, matriculados nos últimos períodos, possam concluir seus cursos.

Implantar essas modificações - considerando que não há nenhuma garantia de quando serão retomadas as atividades presenciais - é questão de respeito aos direitos do corpo discente e, também, de sobrevivência institucional. 